\title{
Exploring the Factors Influencing Saudi Nurses' Intentions to Leave Critical Care Units in Government Hospitals at Qassim Region
}

\author{
Hind Jaman Mohamad Aljumah* \\ Master Student in Nursing Administration, King Abdulaziz University, Saudi \\ Arabia
}

Email: hy7717@yahoo.com

\section{Dr. Maram Ahmed Banakhar}

Assistant Professor in Nursing Administration, King Abdulaziz University, Saudi Arabia

\begin{abstract}
:
The health system is based on major pillars that it cannot continue without, the most important of which are doctors and qualified nursing staff. The departure of nursing staff is one of the dilemmas that threaten the health system. Another place, especially leaving work in intensive care. The current scoping review aims to identify relevant evidence related to the factors influencing nurses' intentions to leave critical care units at governmental hospitals at Saudi Arabia. In this study, the researcher explored that some factors were not covered, so the most of the knowledge gap regarding the factors that contribute to nurses' intentions to leave their current occupations in critical care units at governmental hospitals in Saudi Arabia, are motivation and communication among staff members. As well as, conflict among staff members, Nurse Manager Ability, leadership and support of nurses, and nurse-physician relationships are some of the important factors that contribute to nurses' intentions to leave their current occupations that needs to be studied.
\end{abstract}

Keywords: Factors Influencing, Intentions, Saudi Nurses, Critical Care Units, Governmental Hospitals, Qassim Region 


\section{Introduction}

Nurses play an important role in providing healthcare services; they account for the largest number of workforce in most healthcare systems. Nowadays, the need for nursing has increased, and its shortage is considered a global problem (Sharififard et al., 2019). In addition, with the recent progresses and changes of healthcare systems, the need for more nurses will also increase. Accordingly, along with the existing shortage of nursing, the intention to leave this profession can also exacerbate the shortage (Alilu et al., 2016). This problem is considered one of the major challenges that face healthcare organizations, which led to shortage in nursing, increased work stress and job dissatisfaction (Antwi \& Bowblis, 2018).

Worldwide, critical care units are considered one of the major working areas which are adversely effected by the problem of intention to leave nursing profession (Khan et al., 2019). This could be attributed to several causes such as nurse-to-patient ratio and the number of beds as well as continuous care in this department (Daouda et al., 2021). In Saudi Arabia, the issue of nurses' intention to leave in recent years has been a challenge due to its significant impact on the quality of the healthcare system (Shwaihet and Nasaif, 2015). Moreover, the issue of nurses' intention to leave has a great impact on the quality of healthcare within the healthcare institution, and it also has a significant financial impact on the healthcare institution, as this effect amounts to 38900 to 59700 US dollars per year for each nurse (Wetmore, 2018).

Nurses who are working in critical care are highly exposed to job dissatisfaction and job-related stress compared to other nurses in other departments (Awajeh, et al., 2018). Moreover, one recent study in Saudi Arabia revealed that the majority of the nurses reported a moderate level of stress in the ICU in a government tertiary hospitals (Alharbi \& Alshehry, 2019).

Various factors such as management strategies, lack of adequate workforce, salaries and profits, stress, feeling injustice, and attractive factors in the organization can have an impact on this perception and the career leaving process (Tourani et al., 2016). Alsaqri study (2014) revealed that nurses' intention to leave in Saudi Arabia 
is significantly related to job satisfaction, job stress, and job burnout. The problem is extended within Saudi Arabia, since the nurses in the Kingdom are suffering from stress due to their work which can lead to intention to leave, hence the health status in the country would be affected (Batayneh et al., 2019).

Therefore, this problem leads to the loss of experienced and qualified nurses ( $\mathrm{Al}$ Momani, 2017), which caused shortages in healthcare services and affecting the quality of nursing care (Kaddourah, et al., 2018).

Despite the above-mentioned studies, which have been done in Saudi Arabia about nurses' intention to leave, there is a lack of studies, which considered this problem among nurses in critical care unit. Therefore, the main aim of this scoping review is to review the factors influencing Saudi nurses' intentions to leave critical care units among nurses.

\section{The Aim of the Study}

The current scoping review aims to identify relevant evidence related to the factors influencing nurses' intentions to leave critical care units at governmental hospitals at Saudi Arabia.

\section{Literature review}

This chapter illustrates literature about study topic including search strategy, inclusion and exclusion criteria, and themes. Themes for this literature involve: 1) the demographic and work-related characteristics, 2) quality of life, 3) job satisfaction, 3) stress, 4) leadership style and relationships with managers and colleagues. This chapter include flow diagram, knwlegd gap and conclusion as well.

\section{The main aim of this review}

The main aim of this review is to illustrate the factors influencing nurses' intentions to leave critical care units at governmental hospitals in Saudi Arabia through differ previous studies. 


\section{Search Strategy}

One-step search strategy was used to identify published and unpublished studies relevant to the topic reported in English language texts. This step involved an extensive search in different databases, which are MEDLINE, Cumulative Index Nursing and Allied Health Literature (CINAHL), web of science and EBSCO and PubMed.the period 2010 and 2020 was specifically selected to include all potential studies.

\section{Keywords used in the Review:}

Keywords and searching in the databases included the following "Nursing retention", "nursing experience", "critical care", "intent to turnover", "anticipated turnover", "intention to stay", and "job satisfaction". "intent to leave" " nurses" "nursing staff"

To illustrate how these terms were used, the search commenced with each keyword, and was further developed by grouping and combining terms together by using Boolean operators to achieve the best literature review possible. Using Boolean operators allowed the researcher to broaden or narrow the combined key words or phrases by using AND and OR across all databases.

\section{Inclusion Criteria}

Studies which are included in this revie met the following inclusion criteri

- $\quad$ studies whcich have been published between the years 2010 and 2020

- Full text papers

- Studies which have been published in English

- Primary source that identified the factor influencing intention to leave among nurses in critical care units.

\section{Exclusion criteria}

- Studies, which were not available as, fill texts.

- Studies, which have been applied on population other than nurses. 


\section{Study selection process:}

Included studies were checked and excluded according to the inclusion criteria using the strategy mentioned before, In addition, 109 articles were reviewed and selected through database searches and 69 were excluded. Then, nine articles were excluded because they were not relevant to the stidy topic. Studies excluded after abstract evaluation were thirty, twelve articles of them were excluded because it has been published in language other thanEnglish. Moreover, 18 studies were outside timeframe for studies inclusion. Thus, 10 studies were included in this study.Full-text articles assessed and critically apprised for eligibility $(\mathrm{n}=10)$. Reviewed and included in quantitative strand of the studies $(n=10)$. Therefore, ten full articles were eligible for the study criteria. Appendix 1. Figure 1.

\section{Results}

Following the gathering of the literature, studies were divided into five main themes which are influence nurses intention to leave critical care units, demographic and work-related characteristics,quality of life,job Satisfaction, stress , and Leadership style and relationships with managers and colleagues and a thematic analysis was undertaken. These themes have been generated based on the study aim and specific objectives. After reading published studies, which are related to the study topic, The researcher extracted the main ideas, which are involved in these studies. Thus, the results of these studies made full ideas about these themes and correlation of these ideas have been done.

\section{Theme 1: The demographic and work-related characteristics}

This theme describes the demographic and work-related characteristics as contributing factors to nurses' intentions to leave. Regarding marital status, Albougami (2020) in his cross-sectional study, which aimed at exploring the aspects that affect the intention of nurses who work in Saudi Arabia to leave their current jobs and Jaradat, et al. (2017) in their cross sectional study which aimed at examining gender-specific associations of shift work with mental distress and job 
satisfaction in nurses in Palestine; indicated that nurses who were single had a higher intention to leave their current workplace when compared to nurses who were married.

In contrast, Mazurenko Gupte and Shan (2015) conducted cross-sectional study to examine and compare factors associated with making the decision to vacate a job versus leaving the profession among 9796 nurses in the United States and the study showed that married women had high turnover rates. Regarding different clinical areas, one cross-sectional study was done to investigate burnout and its associated factors as well as its effect on the quality of life of critical care nurses working in Buraydah. The study showed that, nurses working in the outpatient and obstetrics departments had lower intentions of leaving than those in the medical and surgical departments, and intensive care units as mentioned in correlational study done by Alotni, and Elgazzar (2020) to investigate burnout, its associated factors and its effect on self-care among critical care nurses and the study of Albougami (2020).

This finding is congruent with the results of an earlier study that found that nurses from the medical and surgical departments were particularly susceptible to stress (e.g., from pre-admission care, patient ratio, elective surgery care, postsurgery care and monitoring, and dealing regularly with life-and-death situations) compared to other clinical areas (Alharbi, 2016), McCarthy et al., (2010) in their correlational study, which was done to examine the levels of stress experienced by nurses working in an Irish teaching hospital; suggested that uncooperative coworkers in the medical and surgical departments also contribute to high stress levels.

Concerning the monthly gross salaries of nurses, these salaries are considerably related to the intention to leave. It is most certain that expatriate nurses may look for opportunities in other developed countries for higher compensation and better working conditions (Albougami, 2020). 
These findings were also supported by an integrative review assessing the previous literature on nursing turnover in the Saudi Arabian context, which revealed that the monthly gross salary was a determinant of the turnover and intention to leave of nurses (Falatah, and Salem, 2018).

Employment laws that address matters such as recruitment, employment, training and qualification requirements, employment contracts, and working conditions are implemented in Saudi Arabia, although various health-care settings may still implement different compensation schemes (Understanding Employment Law in the Kingdom of Saudi Arabia. 2016). Alasmari, and Douglas (2012) conducted an exploratory and cross-sectional study on nurses to examine the relationship between nurses' job satisfaction and their intention to leave critical care nursing in Saudi Arabia. The study showed that nurses without children reported higher scores with intention to leave. Bivariate correlation analyses revealed that age and length of ICU experience both showed weak, yet statistically significant associations with 12 nurses' intentions to leave. However, 'length of RN experience in the nursing profession' was insignificant.

\section{Theme 2: Quality of Life}

This theme describes the quality of life of nurses as contributing factors to nurses' intentions to leave their jobs. Albougami (2020) and Cruz, et al. (2018) in their cross-sectional study that was done to assess the optimism and proactive coping use of nurses and examined their influence on quality of life; reported that nurses who have better physical and psychological health scores predict lower intentions to leave.

Quality of life provides nurses with the motivation to perform well, whereas poor quality of life may cause them to become unproductive and lead to a decrease in the delivery of care Thus, this phenomenon may motivate them to leave their jobs. Whereas nurses with a better quality of life show a lower intention to leave, therefore, it is recommended to develop interventions to enhance nurses' well-being and work engagement and to promote workforce retention. 
One cross-sectional study was done by Kaddourah \& Al-Tannir in (2018) to assess the quality of nursing work life, to explore the nurses' turnover intention and to examine the correlation between quality of nursing work life and nurses' turnover intention, and another study done by Alotni \& Elgazzar (2020) to investigate burnout, its associated factors and its effect on self-care among critical care nurses; recommended that the study participants were not satisfied about their work life, majority of them have had intention to leave their work. It was concluded that that the quality of work life among nurses has a significant effect on patient care. Moreover, they concluded that burnout and the quality of life scores of these critical care nurses had a negative significance correlation and that these nurses have a high intention to leave.

\section{Theme 3: Job Satisfaction}

This theme describes nurses' job satisfaction as contributing factors to nurses' intentions to leave their jobs.

\section{The factors that contribute to job satisfaction}

The factors that contribute to job satisfaction include salaries, promotions and professional improvement opportunities (Najimi, Goudarzi and Sharifirad, 2012).

Al-Dossary, Vail and Macfarlane, (2012) conducted a cross-sectional study to measure nurses' job satisfaction in Saudi Arabia in a university teaching hospital and to determine the influencing factors among 189 nurses. The study concluded that, work stress as one of the factors that can negatively affect employee productivity and work satisfaction may lead to an individual's intention to leave the nursing profession. In addition, Ibrahim et al., (2016), conducted a cross-sectional study to assess quality of life, job satisfaction and their related factors among nurses working in King Abdulaziz University Hospital in Saudi Arabia among 268 nurses.

The study suggested that poor quality of life could lead to problems later on, including job dissatisfaction and higher job turnover. 
Falatah andSalem (2018) and Albougami, (2020) in their cross-sectional study confirmed that in Saudi Arabia nurses experience moderate job satisfaction levels, which are consistently associated with organizational turnover and the intent to leave their current jobs. The findings of the study by Alasmari \& Douglas, (2012), showed that overall job satisfaction was high and overall intention to leave was moderate among critical care nurses working in Saudi Arabia.

These findings indicate a moderate negative relationship where lower personal satisfaction, higher workload and lower professional support were correlated with greater intention to leave critical care units among RNs working in Saudi Arabia.

Sokhanvaret al., (2018) conducted a cross-sectional study to determine job security and turnover intention and also factors behind turnover intention among 600 hospital nurses who worked in Iran. The study concluded that hospital managers need to develop effective policies to reduce nurse turnover intentions through improving their job satisfaction and working conditions, providing fair compensations, enhancing supportive nursing management, and facilitating competence-based career advancement.

Teruya, Costa \& Guirardello (2019) conducted a cross-sectional study on nurses to evaluate job satisfaction and its relationship with the personal and professional characteristics of the nursing team. The study concluded that there was an ambivalence regarding job satisfaction. The variables of intention of stay in the job and the time spent working at the unit and at the institution were correlated with job satisfaction. Moreover, intrinsic job characteristics are as important as extrinsic job conditions in their effects on ICU nurse job satisfaction. Moreover, Abduelazeez $\&$ Tahir (2016) condiucted a cross-sectional study to study job satisfaction and the factors influencing job satisfaction, to determine the overall level of job satisfaction and to relate socio-demographic characteristic among 125 ICU nurses. The study concluded thatage group and different qualifications are related to nurse job satisfaction level. In addition, intrinsic job characteristics are as important as extrinsic job conditions on ICU nurse job satisfaction. 


\section{Theme 4: Stress}

Albougami, (2020) identifies four variables as significant predictors. Emotional exhaustion, personal accomplishments, physical health and psychological health were identified as significant predictors of the intention to leave. Moreover, Alotni \& Elgazzar, (2020) and Zhang, Huang \& Guan, (2015) concluded that burnout and quality of life scores of critical care nurses had a negative significance correlation. They indicated a moderate distribution of burnout among ICU nurses. They also revealed that an investigation into the burnout levels of this population could bring more attention to ICU caregivers.

A systematic literature review investigating nursing shortages in Saudi Arabia revealed that stress among nurses was the result of excessive working hours and a low nursing staff/patient ratio. This increases the probability that nurses are prone to errors and work fatigue, which can affect the quality of care provided to patients. In addition, this study recommended that further research should be conducted to determine the causes of nurses' stress that might affect their intention to leave their current jobs (Aboshaiqah, 2016).

Zaki, Elsayed \& Ibrahim (2016) conducted a cross-sectional study to explore factors contributing to burnout among Saudi nurses and their effect on patients' satisfaction. The study revealed that less than three quarters $(71.6 \%)$ of nurses had high levels of burnout. They recommended establishing communication skills training programs among healthcare teams to reduce nurses' burnout. Continued administrative support, reinforcement, as well as changing work place environment to reduce nurses' job burnout and to improve patients' satisfaction with care were also recommended.

McElreath (2020) in a cross-sectional study to determine the relationship that exists between burnout, job satisfaction, and intent to leave in nurses who work in the critical care unit within an acute care hospital in the United States. The study results revealed that nurses had significantly high levels of burnout, which contributes to an intent to leave nursing. 
There was a relationship between job satisfaction, burnout, and intent to leave among nurses working in the critical care environment. However, there was no difference between job satisfaction, burnout, and intent to leave among nurses working in critical care units and nurses not working in critical care.

\section{Theme 5: Leadership style and relationships with managers and colleagues}

Alrobai, (2020) in her systematic review to determine the most effective leadership style that can be employed by nurse leaders/managers to increase job satisfaction and prevent burnout among nurses. The results showed that there was a significant positive correlation between transformational leadership and job satisfaction among qualified staff nurses. Moreover, there was a positive relationship between transformational leadership and burnout among staff nurses. This can help nurse managers improve job satisfaction and prevent burnout among staff nurses.

\section{Conclusion}

The aim of the present study is to explore factors influencing nurses' intentions to leave critical care units at governmental hospitals in Saudi Arabia.

The following electronic databases have been searched: MEDLINE, PubMed, CINAHL and EBSCO. Following the gathering of the literature, a thematic analysis was undertaken and five themes emerged from the literature. Theme 1: The demographic and work-related characteristics, Theme 2: Quality of life, Theme 3: Job satisfaction, Theme 4: Stress, and Theme 5: Leadership style and relationships with managers and colleagues. From these themes, it was concluded that, the factors that influence Saudi nurses' intentions to leave critical care units negatively are, working in the medical and surgical departments and intensive care units, increased burnout, poor quality of life, increased work stress, decreased job satisfaction and autocratic Leadership style, however, the factors that influence Saudi nurses' intentions to leave critical care units positively are, decreased burnout, high quality of life, decreased work stress, increased job satisfaction and transformational leadership style. 
Salaries, promotions and professional improvement opportunities are the factors that contributed to job satisfaction. Nurses had significantly high levels of burnout, which contributes to an intent to leave nursing. There is also a positive relationship between transformational leadership and burnout among staff nurses. Nurses without children reported higher scores of intention to leave. Nurses who had better physical and psychological health scores predicted a lower intention to leave. Quality of life provides nurses the motivation to perform well where a poor quality of life may cause them to become unproductive and decrease the delivery of care.

The factors that contributed to job satisfaction included salaries, promotions and professional improvement opportunities. Work stress can negatively affect employee productivity and work satisfaction, which may lead to an individual's intention to leave the nursing profession. Nurses had significantly high levels of burnout, which contributes to an intent to leave nursing. There is also a positive relationship between transformational leadership and burnout among staff nurses. This can help nurse managers improve job satisfaction and prevent burnout among staff nurses.

\section{Knowledge Gap:}

The present findings contribute to the limited literature on the factors that influence nurses' intent to leave their current jobs in Saudi Arabia. This study explored that some factors were not covered, so the most of the knowledge gap regarding the factors that contribute to nurses' intentions to leave their current occupations in critical care units at governmental hospitals in Saudi Arabia, are motivation and communication among staff members.

As well as, conflict among staff members, Nurse Manager Ability, leadership and support of nurses, and nurse-physician relationships are some of the important factors that contribute to nurses' intentions to leave their current occupations that needs to be studied. 
Appendix 1. Figure 1. Prisma adopted from Staneva, et al., (2015).

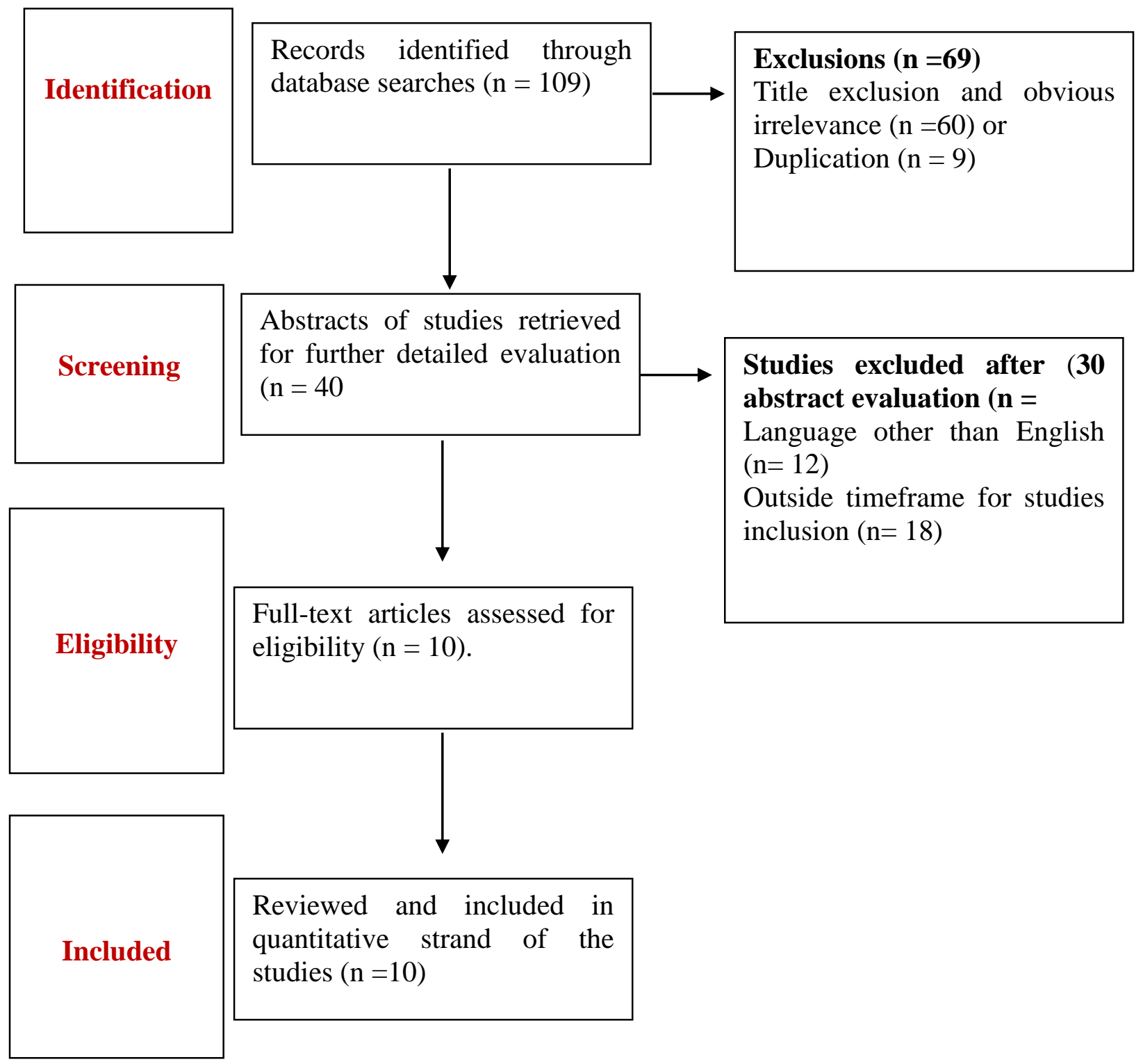

Figure 1. Flow diagram for study selection.

\section{References}

- Abduelazeez, A. E. A., \& Tahir, M. M. (2016). Job satisfaction and related factors among intensive care nurses in governmental hospitals at Khartoum stateSudan. J Comm Pub Health Nurs, 2(2), 114.

- Aboshaiqah A. (2016) Strategies to address the nursing shortage in Saudi Arabia. Int Nurs Rev;63:499-506. 
- Al Momani M. (2017) Factors influencing public hospital nurses' intentions to leave their current employment in Jordan. Int $\mathrm{J}$ Community Med Public Health.;4(6):1847-53.

- Alasmari, H. A. M., \& Douglas, C. (2012). Job satisfaction and intention to leave among critical care nurses in Saudi Arabia. Middle East Journal of Nursing, 6(4), 3-12.

- Albougami, A. S., et al., (2020). Factors affecting nurses' intention to leave their current jobs in Saudi Arabia. International Journal of Health Sciences, 14(3), 33.

- Al-Dossary R, Vail J, Macfarlane F. (2012) Job satisfaction of nurses in a Saudi Arabian university teaching hospital: A cross-sectional study. Int Nurs Rev;59:424-30.

- Al-Dossary R. (2018).The Saudi Arabian 2030 vision and the nursing profession: The way forward. Int Nurs Rev;65:484-90.

- Alharbi J, et al., (2016) The factors influencing burnout and job satisfaction among critical care nurses: A study of Saudi critical care nurse. J Nurs Manage;24:708-17.

- Alharbi MF. (2018) An analysis of the Saudi health-care system's readiness to change in the context of the Saudi national health-care plan in vision 2030. Int $\mathbf{J}$ Health Sci.;12:83-7. [PMC free article] [PubMed] [Google Scholar]

- Almalki MJ FG, Clark M. (2012) The relationship between quality of work life and turnover intention of primary health care nurses in Saudi Arabia. BMC Health Serv Res.;12(1):314-41.

- Altakroni H, et al., (2019) Healthcare productivity, and its sociodemographic determinants, of Saudi female nurses:A cross-sectional survey, Al-Qassim, Saudi Arabia 2017. Int J Health Sci.;13:19-25. [PMC free article] [PubMed] [Google Scholar] 
- Almazan J, Albougami A, Alamri M. (2013) Exploring nurses' work-related stress in an acute care hospital in KSA. J Taibah Univ Med Sci;14:376-82.

- Alonazi N, Omar M. (2013) Factors affecting the retention of nurses. A survival analysis. Saudi Med J;34:288-94.

- Alotni, M. A., \& Elgazzar, S. E. (2020). Investigation of Burnout, its Associated Factors and its Effect on the Quality of Life of Critical Care Nurses Working in Buraydah Central Hospital at Qassim Region, Saudi Arabia. The Open Nursing Journal, 14(1).

- Alrobai, T. (2020). The Impact of Nurse Leaders/Managers Leadership Style on Job Satisfaction and Burnout among Qualified Nurses: A Systematic, IOSR Journal of Nursing and Health Science (IOSR-JNHS)e-ISSN: 2320-1959.pISSN: 2320-1940 Volume 9, Issue 1 Ser. VIII. (Jan -Feb. 2020), PP 17-41.

- Alshareef, A. G., et al., (2020). Identifying factor Influencing Saudi Arabian Nurses' Turnover. Journal of Nursing Management.

- Alshehry A, et al., (2019) Workplace incivility and its influence on professional quality of life among nurses from multicultural background: A cross-sectional study. J Clin Nurs;28:2553-64.

- Antwi, Y. A., \& Bowblis, R. (2018). The impact of nurse turnover on quality of care and mortality in nursing homes: Evidence from the great recession. American Journal of Health Economics, 4(2), 131- 163. https://doi.org/10.1162/ajhe_a_00096.

- Cohen G, Blake RS, Goodman D. (2016) Does turnover intention matter? Evaluating the usefulness of turnover intention rate as a predictor of actual turnover rate. Rev Public Pers Adm.;36(3):240-63.

- Cruz J, et al., (2018) Optimism, proactive coping and quality of life among nurses: A cross-sectional study. J Clin Nurs;27:2098-108. 
- Falatah R, Salem OA. (2018) Nurse turnover in the Kingdom of Saudi Arabia: An integrative review. J Nurs Manage;26:630-8.

- Ibrahim N, et al., (2016) Quality of life, job satisfaction and their related factors among nurses working in king Abdulaziz university hospital, Jeddah, Saudi Arabia. Contemp Nurse;52:486-98.

- Jaradat Y, et al.,. (2017) Shift work, mental distress and job satisfaction among Palestinian nurses. Occup Med;71-4.

- Kaddourah, B., Abu-Shaheen, A. K., \& Al-Tannir, M. (2018). Quality of nursing work life and turnover intention among nurses of tertiary care hospitals in Riyadh: a cross-sectional survey. BMC nursing, 17(1), 43.

- Mahran, G. S., Taher, A. A., \& Saleh, N. M. (2017). Challenges and work crisis facing critical care nurses. Egyptian Nursing Journal, 14(3), 235.

- Mazurenko O, Gupte G, Shan G. (2015) Analyzing U.S. nurse turnover: Are nurses leaving their jobs or the profession itself? J Hosp Adm;4:48-56.

- McElreath, R. L. (2020). A Comparative Analysis of Job Satisfaction, Burnout, and Intent to Leave Among Nurses.

- McCarthy V, Power S, Greiner BA. (2010) Perceived occupational stress in nurses working in Ireland. Occup Med. ;60:604-10.

- McHugh, M. D., et al.,. (2016). Better nurse staffing and nurse work environments associated with increased survival of in- hospital cardiac arrest $\begin{array}{lllll}\text { patients. } & \text { Medical } & \text { Care, } & \text { 54(1), } & 74-\end{array}$ https://doi.org/10.1097/MLR.0000000000000456.

- Najimi A, Goudarzi A, Sharifirad G. (2012) Causes of job stress in nurses: A cross-sectional study. Iran J Nurs Midwifery Res;17:301-5.

- Saquib J, et al. (2019) Job insecurity, fear of litigation, and mental health among expatriate nurses. Arch Environ Occup Health. ;21:1-8. 
- Sokhanvar, M., et al., (2018). Hospital nurses' job security and turnover intention and factors contributing to their turnover intention: A cross-Sectional study. Nursing and Midwifery Studies, 7(3), 133.

- Staneva, A., et al., (2015). The effects of maternal depression, anxiety, and perceived stress during pregnancy on preterm birth: A systematic review. Women and Birth, 28(3), 179-193.

- Teruya, K. Y., Costa, A. C. \& Guirardello, E. D. (2019). Job satisfaction of the nursing team in intensive care units. Revista latino-americana de enfermagem, 27.

- Understanding Employment Law in the Kingdom of Saudi Arabia. (2016).

[[Last accessed on 2016 Nov 14]]. Available from:

https://www.shearman.com/media/Files/NewsInsights/Publications/2016/11/Un derstanding-Employment-Law-in-the-Kingdom-of-Saudi-Arabia-IA11142016.pdf . [Ref list]

- Zaheer S, et al., (2019) Turnover intention of hospital staff in Ontario, Canada: Exploring the role of frontline supervisors, teamwork, and mindful organizing. Hum Resour Health;17:66.

- Zaki, S., Elsayed, L. A., \& Ibrahim, M. M. (2016). Factors contributing to burnout among Saudi nurses and their effect on patients' satisfaction at Makkah Al-Mukaramah hospitals. Life Science Journal, 13(5), 73-88.

- Zhang, X. C., Huang, D. S., \& Guan, P. (2015). Job burnout among critical care nurses from 14 adult intensive care units in northeastern China: a cross-sectional survey. BMJ open, 4(6).

Copyright (C) 2021 Mr. Hind Jaman Mohamad Aljumah, Dr. Maram Ahmed Banakhar, AJRSP. This is an open-access article distributed under the terms of the Creative Commons Attribution License (CC BY NC).

Doi: doi.org/10.52132/Ajrsp.e.2021.295 